\title{
Using DNA to reunify separated migrant families
}

\author{
By Elizabeth Barnert, Sara H. Katsanis, Ranit Mishori, Jennifer K. Wagner, Richard F. Selden, Diana Madden, Dan Berger, Henry Erlich, \\ Kathryn Hampton, Andreas Kleiser, Alessandra La Vaccara, Thomas J. Parsons, Fredy A. Peccerelli, Mariana Herrera Piñero, Michael J. \\ Stebbins, Patricia Vásquez, Curren W. Warf, Thomas J. White, Eric Stover, M. Veronica Svetaz \\ The list of author affiliations is available in the supplementary materials.
}

Email: skatsanis@luriechildrens.org

Fears and perceived lack of tools should not be obstacles

Family separation-whether caused by armed conflict, repressive regimes, disasters, or immigration policies-traumatizes children and parents and can have long-term impacts on physical and mental health $(I)$. It is therefore imperative to develop and deploy policies and tools to support prompt and safe family reunifications and address wrongful government-imposed separations. Given the particular legal, psychological, and medical vulnerabilities of separated migrant families, we propose here a replicable, scalable, and sustainable framework to collect and manage sensitive DNA data to support the reunification of families in a manner that is secure, ethical, and humane, responding to families' needs while minimizing potential risks of government misuse of sensitive data (2). Whether or not families ultimately reunite should be primarily the choice of each family with guidance from supporting agencies, taking into account the child's best interests and family members' safety (I). But lack of tools to connect families, an inability to verify genetic relationships when applicable, and fears of the sensitivity of DNA data should not be barriers.

We define migrant family reunification as a comprehensive approach in which separated family members are identified, reconnected, and provided with legal counsel and psychosocial support. Family separations are an ongoing reality in many global regions and are likely to increase. Scattering of family members often occurs with migration. The United States has seen a surge in migrant families and unaccompanied youth, with more than 70,000 family units and 45,000 unaccompanied minors crossing the border between October 2020 and March 2021. Some family units could face separations; most of the migrant youth are already separated from their families. This follows the separations caused by the Trump administration's "Zero Tolerance" policy to prosecute all undocumented border crossers, officially implemented in April 2018 and prefaced by routine separations starting in 2017 (3). President Biden has since issued an executive order to reunify previously separated migrant families, but the potential role of DNA remains unclear.

Given the substantial harms of family separation, it is critical to ensure the timely and proper use of a DNA database approach, harnessing DNA technology's powerful ability to link genetic families. Most DNA identification applications, including the 2018 efforts in the United States to reunify separated migrant families, are based on 1:1 DNA test comparison, which tests the hypothesis of a relationship, similar to a paternity test. So, in the 2018 attempts, when the DNA of separated Child A was taken, it was sent to a relationship-testing DNA laboratory and held until someone came along claiming a relationship to Child $\mathrm{A}$, in which case a purported parent could provide DNA for the test. By contrast, a database strategy can store DNA of many children and many adults, enabling 1:many searches of each new adult or child to the many children or adults in the database, testing hypotheses of kinship among many possibilities.

We recognize that no technology-including DNA analysis-can reunify all families; however, any inherent limitations are not adequate justification for avoiding the application of scientific tools capable of facilitating the prompt reunification of migrant children and parents.

\section{Learning from the past}

Science-led efforts have resulted in technology, infrastructure, and training materials necessary to launch a DNA-based initiative for reconnecting living displaced and/or missing persons. For example, Argentina's Grandmothers of the Plaza de Mayo, in partnership with geneticists, pioneered the use of DNA to locate children who were disappeared during Argentina's 1976-1983 military dictatorship (4). Geneticists also have assisted the Salvadorian agency Pro-Búsqueda de los Niñas y Niños Desaparecidos to use DNA analysis to locate 384 of the children disappeared during El Salvador's civil war (1980-1992) and illegally adopted in the United States, Europe, and Central America (5). Use of DNA has helped families address "ambiguous loss," the intense trauma when the whereabouts and condition of a missing loved one are unknown (6). It has also allowed families to secure rights to justice, truth, and reparations (7).

Mass victim identification efforts have led to the evolution of approaches for secure management of large DNA datasets while also bringing to light some pitfalls. For example, in the 
aftermath of the 2001 terrorist attacks on the World Trade Center in New York City, forensic scientists harnessed DNA data and database tools, managing and securing sensitive data to identify victims and return their remains to family members for burial (8). The advent of a database approach allowed for ongoing identifications years after the attack. The 2004 tsunami in Southeast Asia (9) and the 2005 Hurricane Katrina (10) demonstrated challenges of DNA data management among multiple nations and jurisdictions, which then fueled improvements in missing-persons communication strategies (11). After the 2010 earthquake in Haiti, DNA identification tools were more successful for foreign visitors than Haitians, indicating a need for equitable access to DNA technologies and better transnational coordination (11).

Entities already exist that can manage large-scale approaches to identifying deceased victims of conflict or forced disappearances. For example, the International Commission of Missing Persons (ICMP), an intergovernmental entity that works to locate missing persons, pioneered the use of a DNAled approach to identify thousands of missing persons in the aftermath of the 1990s' wars in the Balkans (12). By 2020, the ICMP database held DNA data from 101,189 family references and had issued DNA match reports on 20,034 deceased individuals, assisting more than 40 countries to locate missing persons from conflict, human rights abuses, migration, and disasters. As a treaty-based intergovernmental organization that operates independent of any nation member, ICMP benefits from privileges and immunities that guarantee legal protections of data, allowing it to securely hold sensitive personal data-including DNA data-without the risk of seizure by government actors or unauthorized distribution. ICMP is mandated to work in countries only by invitation of the government. ICMP and other similar organizations, such as the Fundación de Antropología Forense de Guatemala, offer technical experience and exemplary processes for using DNA to reunify families who have endured traumatic situations.

The needed DNA technology is available. The most prevalent forensic DNA identification method relies on detection of short tandem repeats (STRs), regions of chromosomes composed of repeated sequences that differ in size between individuals. Because children inherit one copy of each autosomal STR region from each parent, STR analysis is an excellent measure of first-degree genetic relationships but does not generate useful information beyond identity and kinship (13). The global commonality of STRs enables long-term databases for future identifications. Additionally, new tools, such as rapid DNA technologies, have improved the ability to expedite and automate DNA data generation $(14,15)$.

\section{A DNA-led framework}

Prior DNA-based efforts in humanitarian and post-conflict identifications of deceased missing persons have been successful; however, these tools have yet to be adapted globally for identification and reconnection of live missing and displaced persons. We propose an infrastructure to assist migrant family reunifications. Doing so will require procedural adaptation of existing protocols used for the deceased. Our proposal has been tailored to the sociopolitical context of migrant families and addresses potential pitfalls that have restricted prior uses. A DNA-led family reunification framework must be based on a clear understanding of the strengths and limitations of the DNA technology and its uses. Biological sample collection requires families' trust. It must be accompanied with corroborating evidence, such as witness interviews and documentary materials. Alternative approaches for verifying relationships through social networks, interviews, and legal documents are effective for verifying nongenetic, legitimate caregivers. Trust can be earned by approaching families with respect, promoting their agency throughout the reunification process, and applying principles of cultural humility and competency, including fluency in a family's language of choice. Attentiveness to the emotional, legal, and potential physical vulnerabilities families might be facing is paramount.

Establishing close, authentic partnerships with local nongovernmental organizations (NGOs) and ensuring that DNA data remain outside governmental control are core principles anticipated to enhance a family's sense of trust and agency. Collaboration with NGOs is crucial because non-DNA evidence of family relationships is often gathered with NGO support and, in many cases, will be sufficient to establish a relationship. However, DNA can expedite otherwise untraceable kinship associations. Handling data outside of law enforcement and other governmental agencies minimizes the risk of data being misused (for example, for deportation proceedings).

Our goal is to elucidate a framework for the DNA component of the search and reunification process so that, when needed, DNA can be used in parallel with other information. The rationale for such a framework includes the following:

\section{Scientific rigor}

DNA kinship associations through internationally accredited forensic laboratories permit documented and demonstrable rigor for acceptance of results.

\section{Rights protections}

DNA-verified relationships can help to protect rights of children and families. Records on relationships retained by treaty-level organizations could benefit human rights cases. 


\section{Ethical processes}

Guidelines are needed to prevent DNA data use for deportation or in other ways that diminish family members' trust and rights. Addressing ethical and legal pitfalls in advance is critical, such as delineating solutions for database management, informed consent, biological sample collection, chain of custody, analytic standards, and results reporting.

\section{Trauma-informed protocols}

Given the vulnerability of families, approaches attentive to prior trauma and avoidance of further traumatization must be thoughtfully constructed.

\section{Promotingagency}

A science-based, extragovernmental approach equips families to preempt questions about the nature of their personal or familial relationships. If data are not mandated by legal order, families can choose to provide genetic samples or not and can dictate the pace and timing of their reunification process. Informed consent in a language familiar to each individual that takes into account factors such as age and legal vulnerabilities is an important tenet of agency.

The protocol calls for a third party to coordinate the connections while leaving sensitive demographic and biogeographic data in the hands of advocacy organizations and/or attorneys working with families (see the figure). The thirdparty team must be accountable to families and operate without bias or special interests as a cooperative coalition, with input and representation from a multinational, multicultural group of stakeholders. Data collected for family reunification should be used only for family reunification and not to support persecutions, discrimination, or criminal identification, including screening for human trafficking. Furthermore, it should only be used to identify matches and not to prove lack of kinship. Both requirements can be met through a database strategy. Lack of a match (such as might result from misattributed parentage, adoptions, or other nongenetic relationships) only indicates that no genetic relative is in the database, and this need not be communicated, enhancing data safeguards; 1:1 genetic relationship tests can undermine the value of DNA data, raising questions on identity if the DNA test does not verify the family connection. By contrast, when a match is made by using a database approach, indicating that a genetic parent and child have been found, advocacy organizations and/or attorneys working with family members should be immediately notified of results. They should in turn notify the parties involved, guided by the tenet of the best interest of the child. Depending on each situation, it might or might not be in the child's best interest to reunite physically with biological parents or other relatives. Supporting advocacy organizations and lawyers can provide counseling and guidance that prioritize children and biological family members' wishes on how they would like to proceed once notified of a DNA match. Although we support the use of DNA data outside of government control, government cooperation is essential for promoting the wellbeing and safety of families.

For the purposes of parent-child DNA analysis to facilitate potential reunification, STR analysis is almost always sufficient. For sibling relationships, STR analysis is usually effective. For grandparent-grandchild, avuncular relatives, and half-siblings, STR analysis is occasionally effective. STR analysis is rarely useful in assessing more distant relationships and never useful in assessing adoptions by nonbiological parents. For families for whom references are available only from lone and/or more distant relationships, other DNA analysis methodologies [such as single-nucleotide polymorphism (SNP) or genome sequencing analysis] can be informative. These alternative methodologies are capable of revealing clinical and phenotypic information and therefore have a greater potential for misuse than that of STR data. The broad utility of STR analysis in kinship combined with the absence of health or phenotypic information in the resulting DNA data presents an appropriate risk-benefit profile for use as the primary DNA identification modality in familial reunification. In cases in which STRs are insufficient, SNP analysis and DNA sequencing can be used with appropriate data safeguards. Use of SNP or genomic data should include only those data necessary for identification and exclude genomic data that might allude to geographical origin or cultural belonging.

Our suggested approach addresses only verification of genetic connections among separated migrant families. Further refinement and iterations are essential to ensure security of data, sustainability, and responsiveness to migrant families' needs and the dynamic legal, cultural and emotional context of the family separations. Careful attention to the development of appropriate consent processes is needed. All processes must be in conjunction with protocols that guarantee the safety and humane treatment of those affected and ensure respect for the culture and customs of families.

\section{Identity and opportunity}

The expanding uses of genetic information in immigration contexts will likely prompt governments to deploy DNA tools in some manner. We must therefore work to ensure that this is done responsibly, with international guidelines and best practices for a DNA-led approach for reunification of migrant families; strategies to manage DNA data at an international level; and ongoing input from experts, including families, advocates, scientists, and government agencies. ICMP has the tools, protections, and infrastructure to expand their expertise in identifications on the deceased to manage DNA data of living, missing persons cases, should they be 
invited by governments to coordinate. Successful outreach to families will require close partnership with existing NGOs that serve migrant families. What is needed is a third-party entity or a network of experts in an advisory role to coordinate the initial effort and provide guidance on the use of DNA for reunifying migrant families. The role of DNA is to identify genetic relationships so that children can restore their familial identity and have the opportunity to reunite with their families. DNA should be used when lack of evidence to support a child or biological family member's location or identity might prevent reunification. Our proposed framework can help signatory States fulfill mandates under Article 9 of the United Nations (UN) Convention on the Rights of the Child, uphold the principles in Article 23(1) of the UN International Covenant on Civil and Political Rights, and address mandates under the International Convention for the Protection of All Persons from Enforced Disappearances. If developed properly, with trauma-informed approaches and international-level protections for sensitive genetic data, the approach described here can help shorten family separations, lessening years of anguish and trauma from ambiguous loss, so that healing can begin.

\section{REFERENCES AND NOTES}

1. Council on Community Pediatrics, Providing care for immigrant, migrant, and border children. Pediatrics 131, e2028-e2034 (2013). doi:10.1542/peds.20131099 Medline

2. E. Holland, Calif. Law Rev. 99, 1635 (2011).

3. Joint Status Report (Document 556, filed 10/20/20). Ms. L et al. vs. U.S. Immigration and Customs Enforcementet al., case no. 18cv428 DMS MDD. United States District Court, Southern District of California (2020).

4. M. H. Piñero, E. Stover, M. Tupa, V. B. Penchaszadeh, in Silent Witness: Applying Forensic DNA Analysis in Criminal and Humanitarian Disasters, H. Erlich, T. White, E. Stover, Eds. (Oxford Univ. Press, 2020), chap. 7.

5. E. S. Barnert, E. Stover, G. Ryan, P. J. Chung, Long Journey Home: Family Reunification Experiences of the Disappeared Children of El Salvador. Hum. Rights Q. 37, 492-510 (2015). doi:10.1353/hrq.2015.0028

6. P. Boss, Ambiguous Loss: Learning to Live with Unresolved Grief (Harvard Univ. Press, 2000).

7. A. Nelson, The Social Life of DNA: Race, Reparations, and Reconciliation After the Genome (Beacon Press, 2016).

8. J. D. Aronson, Who Owns the Dead?: The Science and Politics of Death at Ground Zero (Harvard Univ. Press, 2016).

9. O. W. Morgan, P. Sribanditmongkol, C. Perera, Y. Sulasmi, D. Van Alphen, E. Sondorp, Mass fatality management following the South Asian tsunami disaster: Case studies in Thailand, Indonesia, and Sri Lanka. PLOS Med. 3, e195 (2006). doi:10.1371/journal.pmed.0030195 Medline
10. S. M. Dolan, D. S. Saraiya, S. Donkervoort, K. Rogel, C. Lieber, A. Sozer, The emerging role of genetics professionals in forensic kinship DNA identification after a mass fatality: Lessons learned from Hurricane Katrina volunteers. Genet. Med. 11, 414-417 (2009). doi:10.1097/GIM.0b013e3181a16ccc Medline

11. A. J. London, L. S. Parker, J. D. Aronson, Public health. DNA identification after conflict or disaster. Science 341, 1178-1179 (2013). doi:10.1126/science.1238085 Medline

12. T. J. Parsons, R. M. L. Huel, Z. Bajunović, A. Rizvić, Large scale DNA identification: The ICMP experience. Forensic Sci. Int. Genet. 38, 236-244 (2019). doi:10.1016/i.fsigen.2018.11.008 Medline

13. S. H. Katsanis, J. K. Wagner, Characterization of the standard and recommended CODIS markers. J. Forensic Sci. 58 (Suppl 1), S169-S172 (2013). doi:10.1111/i.1556-4029.2012.02253.x Medline

14. C. Carney, S. Whitney, J. Vaidyanathan, R. Persick, F. Noel, P. M. Vallone, E. L. Romsos, E. Tan, R. Grover, R. S. Turingan, J. L. French, R. F. Selden, Developmental validation of the ANDE ${ }^{T M}$ rapid DNA system with FlexPlex ${ }^{T M}$ assay for arrestee and reference buccal swab processing and database searching. Forensic Sci. Int. Genet. 40, 120-130 (2019). doi:10.1016/i.fsigen.2019.02.016 Medline

15. S. Jovanovich, G. Bogdan, R. Belcinski, J. Buscaino, D. Burgi, E. L. R. Butts, K Chear, B. Ciopyk, D. Eberhart, O. El-Sissi, H. Franklin, S. Gangano, J. Gass, D. Harris, L. Hennessy, A. Kindwall, D. King, J. Klevenberg, Y. Li, N. Mehendale, R. McIntosh, B. Nielsen, C. Park, F. Pearson, R. Schueren, N. Stainton, C. Troup, P. M. Vallone, M. Vangbo, T. Woudenberg, D. Wyrick, S. Williams, Developmental validation of a fully integrated sample-to-profile rapid human identification system for processing single-source reference buccal samples. Forensic Sci. Int. Genet. 16, 181-194 (2015). doi:10.1016/i.fsigen.2014.12.004 Medline

\section{ACKNOWLEDGMENTS}

E.B. and S.H.K. contributed equally and E.S. and M.V.S. contributed equally to this work. The authors thank all DNA Bridge consortium members, and appreciate $\mathrm{C}$. Easter, A. Forcinito, E. Henderson, and C. Kapustij for early contributions. We acknowledge Cristián Orrego Benavente (now deceased) for his scholarship on DNA applications and for connecting many of the co-authors. Funding: This work was supported by the National Institute on Drug Abuse grant K23 DA045747-01 (E.B.); California Community Foundation grant BAPP-19-154836 (E.B.); University of California, Los Angeles, Children's Discovery and Innovation Institute (E.B.); National Human Genome Research Institute grant R01HG009923 (S.H.K., D.M., J.K.W., and D.B.); and Minnesota Department of Health Eliminating Health Disparities Initiative (M.V.S.) Views are those of the authors and not necessarily those of their institutions or funders.

\section{SUPPLEMENTARY MATERIALS}

science.sciencemag.org/cgi/content/full/science.abh3979/DC1

Published online 27 May 2021

10.1126/science.abh3979 


\section{A DNA-led database strategy for migrant family reunifications}

The graphic delineates the parallel paths for DNA data collection for reunification of families separated as a result of the 2018 U.S. Zero Tolerance policy. NGO, nongovernmental organization; STRs, short tandem repeats.

Migrant children

separated from families

Adults separated from migrant children

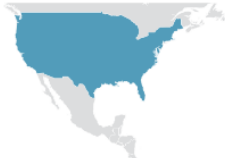

Third-party reunification team

- Coordinates logs of outreach

- Manages mouth swab collections

- Coordinates NGO connections

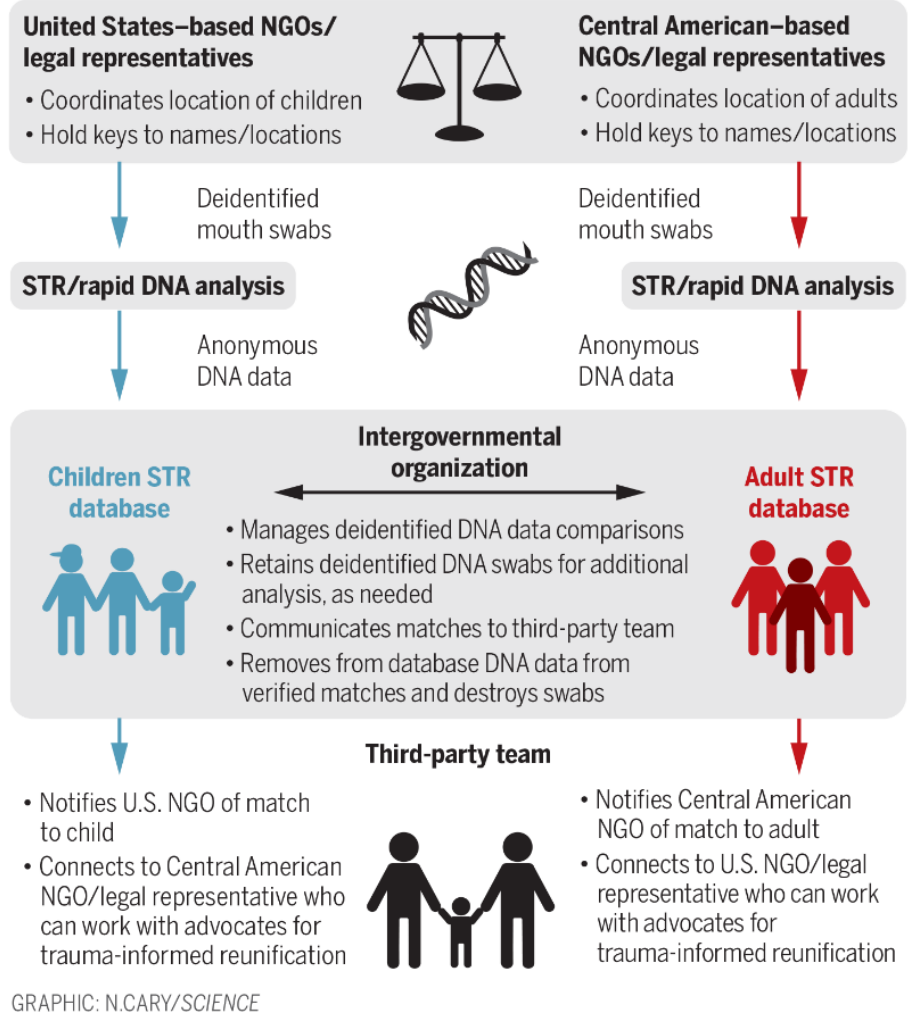

